\title{
Information on EFMI Working Groups
}

\author{
Rolf Engelbrecht', John Mantas ${ }^{2}$ \\ 'BMI, Ismaning, Germany \\ ${ }^{2}$ Health Informatics Laboratory, Faculty of Nursing, University of Athens, Greece
}

EFMI is a nonprofit organisation concerned with the theory and practice of Information Science and Technology within Health and Health Science in a European context. Its activities focus on annual conferences, MIE (Medical Informatics Europe), STC (Special Topic conference), tutorials and workshops. EFMI publishes proceedings and special issues of its activities in scientific journals and books. It has national societies in 32 member countries in the WHO-region Europe and 16 institutional members. Personal members are welcome in working groups. The EFMI portal provides very actual international news and information about research and use of computers in health care. http://www.EFMI.org.

\section{Working Groups}

EDU - Education in Health Informatics

John Mantas, Athens; Arie Hasman, Amsterdam (jmantas@cc.uoa.gr, a.hasman@amc.uva.nl)

EHR - Electronic Health Records Bernd Blobel, Regensburg (bernd. blobel@klinik.uni-regensburg.de)

EVAL - Assessment of Health Information Systems

Elske Ammenwerth, Innsbruck;

Pirkko Nykanen, Tampere; Jytte

Brender, Aalborg

(elske.ammenwerth@umit.at, Pirkko.Nykanen@stakes.fi, jytte.brender@v-chi.dk )
HIIC - Health Informatics for Interregional Cooperation Lacramioara Stoicu-Tivadar, Timisoara; (lacramioara.stoicutivadar@aut.upt.ro)

HOFMI - Human and Organisational Factors of Medical Informatics Jos Aarts, The Netherlands; MarieCatherine Beuscart-Zéphir, Lille, France(j.aarts@bmg.eur.nl, mcbeuscart@univ-lille2.fr)

IDR - Informatics for the Disabled and Rehabilitation Cristina Mazzoleni, Italy (cmazzoleni@fsm.it)

LIFOSS -Libre/Free and Open Source Software in Health Informatics Thomas Karopka, Germany (TKaropka@googlemail.com)

MCRO/MBDS - Casemix, Resources Management and Outcomes of Care Francis Roger-France, Brussels; Jacob Hofdijk, Leiden (frf@skynet.be, jhofdijk@gmail.com)

MIP - Medical Image Processing Alexander Horsch, Munich; Thomas Wittenberg, Germany; Vytenis Punys, Kaunas (alexander.horsch@imse.med.tumuenchen.de,wbg@iis.fhg.de, vpunys@mmlab.ktu.lt)
NLU - Natural Language Understanding Patrick Ruch; Robert Baud, Geneva (patrick.ruch@sim.hcuge.ch, Robert.Baud@sim.hcuge.ch)

NURSIE - Nursing Informatics in Europe Patrick Weber, Lausanne; Thomas Buerkle, Erlangen (patrick.weber@nicecomputing.ch, thomas.buerkle@imi.med.unierlangen.de)

PCI - Primary Care Informatics Simon De Lusignan, London (slusigna@sgul.ac.uk)

PPD Personal Portable Devices Paul Cheshire, UK; Peter Pharow, Illmenau (efmi_ppd@yahoo.co.uk, Peter.Pharow@web.de)

SSE - Safety, Security and Ethics Bernd Blobel, Regensburg (bernd.blobel@klinik.uniregensburg.de)

TRACE - Traceability of supply chains

Christian Lovis, Geneva

(christian.lovis@hcuge.ch) 


\section{Information on EFMI Working Groups}

\section{EFMI WG EDU}

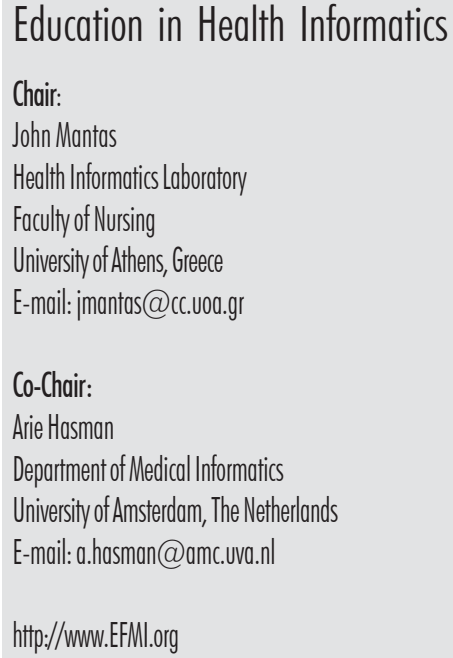

\section{EFMI WG EHR}

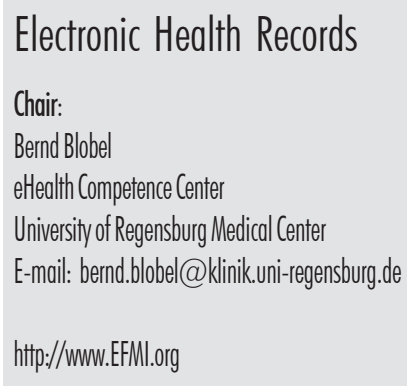

\section{Objectives:}

- To disseminate and exchange information on Health and Medical Informatics (HMI) programs and courses.

- To advance the knowledge of how HMI is taught to health care professionals, to students in Europe

- To promote a database on programs and courses on HMI education

- To produce international recommendations on HMI education

- To support HMI courses and exchange of students and teachers.

\section{Recent and Future Activities:}

- Preparation of an revised version of Globalization of Health Informatics Education, Studies in Health Technology and Informatics, Edited by: E.J.S. Hovenga and J. Mantas, 276 pp., IOS Press, 2004

- Recent discussions of WG members initiated the revision of IMIA recommendations on HMI Education.

- The document of the revised recommendations was presented during a Conference Buenos Aires in November 2008. It was prepared by the Task Force chaired by the EFMI WG Chair on Education. At MIE2009 in Sarajevo the revised educational recommendations were presented

- Collection of data to update the database of programmes and courses on the WG website.

- A work will be initiated and coordinated to develop skills and competencies in the field of Biomedical and Health Informatics.

\section{Objectives:}

The working group deals with the issue electronic health records in the different levels of development: case level, organisational level, regional level, national level, and international level. The Working Group supports

- Studies on specification, implementation, and promotion of standards for EHR

- Modelling of EHR architectures

- Education in EHRs

\section{Recent and Future Activities:}

- Workshop „The Role of Ontologies for Sustainable, Semantically Interoperable and Trustworthy EHR Solutions" at MIE 2000*

- Workshop „HL7's Comprehensive Standard Set and Its International Collaboration for Enabling Semantically Interoperable eHealth and pHealth Solutions" at MIE 2009, Sarajevo, Bosnia and Herzegovina, jointly organized with HL7 International

- Contributions to the HIIC-Workshop „Is there a Common Background to Support Better Healthcare in Central and South East Europe?" at MIE 2009, Sarajevo

- Session „EHR and Standards“ at the EFMI STC 2009, Antalya, Turkey

- Workshop at the EFMI STC 2010, Reykjavík, Iceland*

- Workshop at ICMCC 2010 in London, UK. *

Activities results are published. 


\section{EFMI WG EVAL}

Assessment of Health Information
Systems
Chair:
Elske Ammenwerth
UMIT - Universityfor Health Sciences, Medical Informatics
and Technology
Hall in Tyrol,Austria
E-mail: elske.ammenwerth@umit.ot
Co-Chairs:
PirkkoNykanen
Facultyfor InformationSciences
Tampere University, Finland
E-mail: pirkko.nykanen@stakes.fi
Jytte Brender
Aalborg University, Denmark
E-mail: iytte.brender@v-chi.dk
hittp://EVaL.EFMl.info

Health Informatics for Interregional Cooperation

Chair:

Lacramioara Stoicu-Tivadar

University "Politehnica" Timisoara

Timisoara, Romania

E-mail:lacramioara.stoicu-tivadar@aut.upt.ro

http://www.EFMl.org

\section{Objectives:}

- To foster interdisciplinary discussion on evaluation issues in health informatics.

- To support communication of experiences by organizing tutorials and workshops.

- To promote European networking on evaluation issues in health informatics.

\section{Recent and Future Activities:}

- STARE-HI, the Standards for Reporting on Evaluation Studies in Health Care, has been adopted by EFMI and IMIA and is available for free at the IMIA website (http://www.imia.org/endorsed/endorsed.lasso). It has also been reprinted in the IMIA Yearbook 2009. The working group is now working on STARE-HI recommendations on how to structure an evaluation paper.

- The working group started work on a mini-STARE-HI for conference proceedings. Here, an expert survey has been conducted on elements relevant for conference evaluation papers. Now, a study is underway to analyze the quality of previous conference papers.

- The work on the Good Evaluation Practice Guidelines (GEP-HI) is advancing quickly. Those guidelines describe the activities, roles and outcomes of an IT evaluation study in health care. Working documents on GEP-HI can be found at http://iig.umit.at/efmi.

- Workshops on „GEP-HI: Introducing guidelines for good evaluation practice in health informatics" were held at AMIA2009 in San Francisco and at MIE2009 in Sarajevo. Comparable workshops are planned for Medinfo2010.

- The working group will support ICICTH2010 in Samos by presentations.

\section{Objectives:}

- To promote exchange of information and experiences between actors in Europe, especially in developing regions

- To investigate the needs, opportunities and obstacles for e-health and to review and select from different education options for developing regions.

- To disseminate European and world-wide results and experiences across regions and between professionals

- To facilitate access to European groups and their facilities and outcomes by students and health professionals from developing regions

- To disseminate European and world-wide results and experiences across developing regions and professionals

\section{Recent and Future Activities:}

- Support for Serbia and Moldavia to relate to European documents and possibilities of financing of health informatics projects.

- MIE2009, Sarajevo, organizing the Workshop „Is There a Common Background to Support Better Healthcare in Central and South East Europe?" - to asses healthcare informatics stage for 6 countries in Central and East European area, and the real need for cooperation and its driving forces.

- Initiation of a regional co-operation forum.

- Starting from 2009 a Master degree in Information Systems in Healthcare, a unique cooperation in the area between a Technical University and a Medical University in order to prepare specialized staff in healthcare informatics having different backgrounds.

- Supporting organisation of EFMI-STC 2011, Ptuj, Slovenja. 


\author{
EFMI WG HOFMI \\ Human and Organisational Factors of \\ Medical Informatics \\ Chair: \\ Jos Aarts \\ Erasmus University Medical Center \\ Rotterdam, The Netherlands \\ E-mail: j.aarts@bmg.eur.nl \\ Co-Chair: \\ Marie-Catherine Beuscart-Zéphir \\ Universitéde lille \\ Lille, France \\ E-mail:mcheuscar@@univ-lille2.fr \\ http://www.EFMl.org

\section{EFMI WG IDR} \\ Informatics for the Disabled and \\ Rehabilitation \\ Chair: \\ Cristina Mazzoleni, Italy \\ E-mail: cmazzoleni@fsm.it \\ hitp: //www. EFMl.org
}

\section{Objectives}

- To organize workshops and tutorials dedicated to the WG topics

- To establish networks of people involved in human and organizational issues in the healthcare domain, and to learn about new developments and their activities

- To disseminate knowledge about human and organizational factors in medical informatics by various activities, such as conferences, educational events, publications.

\section{Recent and Future Activities:}

- 4th conference „Information Technology in Health Care: Sociotechnical Approaches“, Sydney, Australia, 28 - 30 August 2007. The conference also included a doctoral colloquium. Papers published in „Studies in Health technology and Informatics“, Vol. 130, IOS Press. There were over 100 participants. A selection of the best papers will be published in a special issue of the International Journal of Medical Informatics.

- A business meeting took place at MIE2008 in Göteborg, including paper presentations.

- The Fourth International Conference IT in Health Care: Sociotechnical Approaches (ITHC2010) at the University of Aalborg (Denmark) on 23 and 24 June 2010 will be supported. The theme of the conference is „From safe systems to patient safety."

\section{Objectives:}

- Support of research, developmental work and education/information in the field through a systematic progressive collection of the relevant literature and the promotion of a discussion forum

- To promote a multidisciplinary collaboration among the healthcare and informatics professionals on one hand, and the consumer associations on the other hand in order to pursue, and also spread the culture of, accessibility and usability.

- To involve researchers belonging to different disciplines and users through the organization of workshops

\section{Recent and Future Activities:}

- STC 2008, London September 9-11 2008

Open Source Software and Disability with Rehabilitation: Desert with Few Oases

- $7^{\circ}$ ICICTH - Samos 16 July 2009

Continuity of Care in Rehabilitation

- STC 2009, Antalya 12-14 ${ }^{\text {th }}$ November 2009

- Session in the conference related to the different kinds of support provided by informatics and computer-based system in order to facilitate mobility and inclusion of people with special needs and distance rehabilitation.

- Italian Society for rehabilitation of high specialization (SIRAS) conference 26$27^{\text {th }}$ November 2009

During the conference EFMI was presented with special focus on the potentiality of a collaboration between Siras and EFMI in the specific area of ICT usage.

- Organization of an international workshop on tele-rehabilitation and e-inclusion, February 2010 


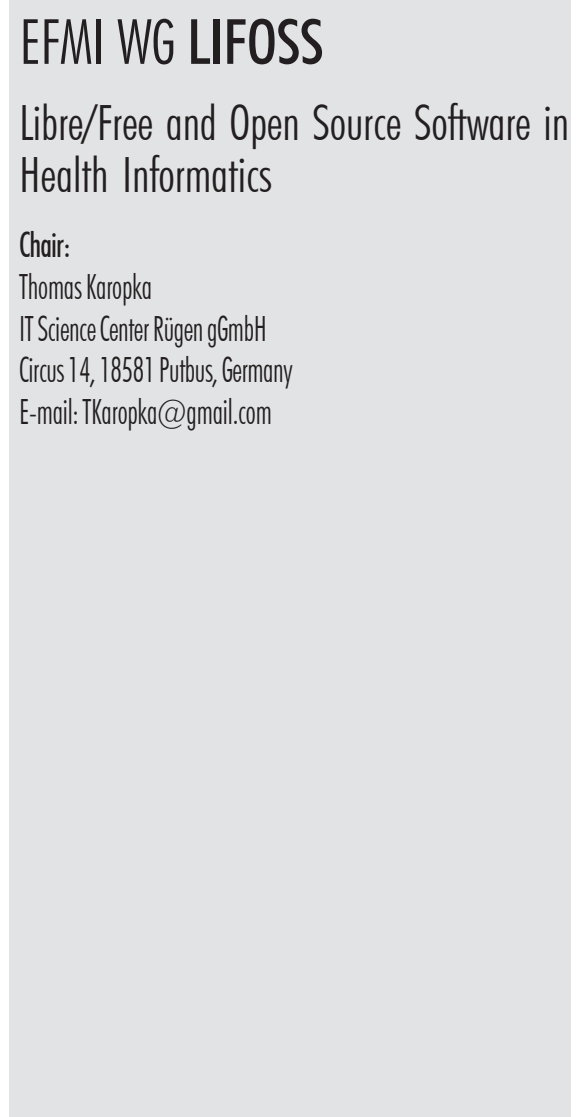

EFMI WG MCRO

MBDS - Casemix, Resources Management and Outcomes of Care

Chair:

F.H. Roger France

Centre for Medical Informatics

University of Louvain, Brussels

E-mail:ff@skynet.be

Co-Chair:

Jacob Hofdijk

Leiden, The Netherlands

E-mail:|hofdij|k@dbconderhoud.nl

http://www.EFMl.org

\section{Objectives:}

- evaluation of free/libre and open source materials and approaches

- exploration and development of open standards

- use of free/libre and open source systems, and knowledge transfer about these systems

- a European focus, including activities aimed at, but not exclusive to, the European Union.

\section{Recent and Future Activities:}

- January 2009, First International Workshop on Open Source in European Healthcare - OSEHC2009, Porto, Portugal

- April 2009, Workshop Sustainable Collaborations in health care Open Source Software, Med-e-Tel 2009, Luxembourg

- September 2009, Workshop Open Source and health care in Europe - Time to put leading edge ideas into practice, MIE2009, Sarajevo

- January 2010, Special Session OSEHC 2010, Valencia, Spain

- February 2010, Co-organization of IWEEE 2010, Las Palmas, Spain www.iweee.org

- April 2010, FLOSS-HC track at Med-e-Tel 2010, Luxembourg

- A website has been created for informal coordination of the group at: http:// groups.google.com/group/efmi-lifoss-wg

- For our future work we would like to foster close cooperation with other FLOSS in health care groups like IMIA OS WG and AMIA OS WG and also with social networks like OpenHealthCare Group on LinkedIn

\section{Objectives:}

- The organisation of special topic conferences, workshops, teaching sessions in the European Region

- The communication of up to date experiences and/or references between members, including national data sets, terminology, coding system and patient classification methods for resource management and quality of care

- The dissemination of results about informatics tools and telematics systems in this specific area among EFMI and IMIA affiliated members and participants to their meetings.

\section{Recent and Future Activities:}

- MIE2008 - Working group session on Casemix and Integrated Care, CHAINE Revisited

- PCSI 2008 Lisboa, Workshop on Casemix and Chronic Disease Management.

- MIE2009 / Joint Session with CONTSYS about Continuity of Case and Casemix tools for Chronic Disease Management.

- Special Session on Casemix during the STC2010 in Iceland on Casemix and Chronic Care.

- Working Group Meeting : Future of Casemix and Health IT:

a Call to candidates is made to all EFMI and IMIA members having casemix activities, in order to organise an ,internet and local meeting“ during Medinfo 2010 on quality of care, using comparable Minimum Basic Data Sets with special focus on chronic conditions, which has been promoted by the working groups since MIE 2005. Deadline for the call: 1 Sept. 2010 


\section{EFMI WG MIP \\ Medical Image Processing \\ Chair: \\ Alexander Horsch \\ Technical University Munich, Munich, Germany \\ E-mail: dlexander.horsch@imse.med.tu-muenchen.de \\ Dept. of Clinical Medicine \& Dept. of Computer Science \\ University of Tromso \\ N-9037 Tromso, Norway \\ E-mail:horsch@cs.uit.no \\ Co-Chairs: \\ Thomas Wittenberg \\ Fraunhofer Institute for Integrated Circuits IIS \\ Dept. of Image Processing and Medical Engineering \\ E-mail:wbg@iis.fhg.de \\ Vytenis Punys \\ Image Processing \& Analysis Lab \\ Computational Technologies Centre \\ Kaunas University of Technology \\ Kaunas, lithuania \\ E-mail:vpunys@mmlab.ktu.lt \\ http://www.efmi-wg-mip.net}

\section{EFMI WG NLU}

Natural Language Understanding

Chairs:

Patrick Ruch

Service d'Informatique Médicale

Hôpitaux Universitaires de Genève

CH-1211 GENEVA 14 Switzerland

E-mail:Patrick.Ruch@sim.houge.ch

and

RobertBaud

Service d'Informatique Médicale

Hôpitaux Universitaires de Genève

CH-1211 GENEVA 14 Switzerland

E-mail:Robert.Baud@sim.hcuge.ch

hitp://mww.EFMl.org

\section{Objectives:}

- Support of communication and common attempts of academia and industry to increase quality of innovation, research and development in the field of medical image processing.

- A reference image database for medical image processing R\&D groups (RIDMIP) and a web-based Information System (IS) about European Image Processing including Groups and their current activities.

- to maintain the MIP website and establish a web-based information system for European image processing groups and their current activities.

- To organise and conduct workshops at EFMI conferences and other events.

- To build and maintain close relationship with persons, groups, organisations and standardisation bodies.

\section{Recent and Future Activities:}

- The WG is meanwhile successfully using the 3helix.org platform of 3helix Institute at University of Hawaii for CSCW-enhanced collaboration between meetings.

- At CARS2009 in June 2009 in Berlin, the WG organized the $1^{\text {st }}$ CADdemo@CARS workshop for demonstration of computer aided diagnosis research prototypes.

- Furthermore, the 18th CATAI Winter Course of the University of La Laguna, Tenerife, Spain, in March 2010 will be supported by a presentation of recent DICOM developments.

- The 2nd CADdemo@CARS workshop and an accompanying business meeting are planned to be held at CARS 2010 in Geneva. It is also planned to actively contribute to MIE 2011 in Oslo.

\section{Objectives:}

- To organize events, such as workshops and conferences dedicated to NLP (Natural Language Processing);

- Networking with persons and societies involved in NLP in the medical domain, especially in Europe, and to learn about their current developments and activities. To develop connections with experts in the general NLP domain and to participate to related events (ACL, COLING...);

- To represent EFMI at IMIA WG6 and at AIME. To support their events.

\section{Recent and Future Activities:}

- WG NLU has established connections with leading EU initiatives in the domain of and Analysis of Clinical Reports, such as DebugIT (http:// www.debugit.eu/); PSIP (http://www.psip-project.eu/), as well as callEPSO.

- Various applications and services have been developed and maintained, e.g. the SNOCat automatic medical encoding tool for SNOMED CT: http://eagl.unige.ch/ SNOCat/; and the EAGLi medical question-answering framework: http:// eagl.unige.ch/EAGLi/.

- The prospective of participation to the EU FP7 call for projects is going on, including the Innovative Medicine Intiative, where Text Mining plays a central role.

In January 2010, a DebugIT winter shool dedicated to semantic interoperability in biomedicine, was scheduled in Paris (http://www.debugit.eu/documents/ DebugITwinterschool2010.pdf). Topics such as Text Mining, Question-Answering and their relationship with Decision-support were discussed. 


\section{EFMI WG NURSIE}

\author{
Nursing Informatics in Europe \\ Chair: \\ PatrickWeber \\ Nice Computing Ch. \\ Lausanne, Switzerland \\ E-mail:patrick.weber@nicecomputing.ch \\ Co-Chair: \\ Thomas Buerkle \\ Universität Erlangen \\ Erlangen, Germany \\ E-mail:thomas.buerkle@imi.med.uni-erlangen.de \\ Secretary: \\ Janette Bennett \\ Peterborough, United Kingdom \\ E-mail: janette.bennett@bt.com \\ http://wwww.nicecomputing.ch/nieurope
}

\section{EFMI WG PCI}

Primary Care Informatics

Chair:

Simon de Lusignan

Primary Care Informatics

Department of Community Health Sciences

St. George's Hospital Medical School

London, UK

E-mail:slusigna@sgul.ac.uk

http://www.EFMl.org

\section{Objectives:}

- To support nurses and nursing organizations in the European countries (18 members) with information and contacts and the field of medical informatics

- To offer nurses opportunities to build contact networks within the informatics field.

- To support the education of nurses with respect to informatics and computing.

- To support research and developmental work in the field and promote publishing of achieved results.

\section{Recent Activities:}

- MIE2008 preconference nursing workshop on May $25^{\text {th }}$ prepared together with by NSF (Norwegian Nurses' Organization) NSFID (Norwegian Nurses' Organization's Special Interest group on Nursing Informatics), Orebro University and IMIA NI working group. The speakers and the experts gave a good overview on "Preparing for eHealth - collaborative efforts in nursing".

- During WoHIT 2008 conference November $3^{\text {rd }}$ a full day conference "What Can Technology and Informatics Do for You?" at Herlev Hospital

- Support of the first Croatian Nursing informatics conference in Zagreb November $7^{\text {th }}$ to $11^{\text {th }} 2008$

- Second version of "Nursing and Informatics for $21^{\text {st }}$ Century" published together with Ch. Weaver, C. Delaney, P. Weber and R. Carr will be ready February 2010.

\section{Definition}

Primary Care Informatics is the scientific study of data, information and knowledge, and how they can be modelled, processed or harnessed to promote health and develop patient-centred primary medical care.

Its methods reflect the biopsychosocial model of primary healthcare and the longitudinal relationships between patients and professionals.

Its context is one in which patients present with unstructured problems to specially trained primary care professionals who adopt a heuristic approach to decision making within the consultation. (JAMIA 2003;10:304-309)

\section{Objectives:}

This Working Group aims to further develop the theoretical basis for best practice, which should underpin the use of Informatics in Primary Care.

- To advance pan-European cooperation and the dissemination of information in the domain of primary care informatics.

- To promote high and common standards of applications used in primary care with a focus on the usability of technology in primary care.

- To promote research and development aimed at developing a core generaliseable theoretical basis for primary care informatics.

- To encourage high standards in education

\section{Recent and Future Activities:}

- Workshop at the EFMI STC 2008 London, UK, launching the ALFA toolkit. This is a multi-channel video method of precisely observing the impact of the computer on the clinical consultation (www.jmir.org/2008/4/e27/).

- Involvement in the TRANSFoRm. project - which is setting out to develop a template for an electronic primary care research network across Europe and improved decision support. Our working group workshops at EFMI meetings will focus on understanding the barriers to sharing health data. (www.transformproject.eu)

- A combined workshop with IMIA and other regional informatics associations at MEDINFO 2010. 


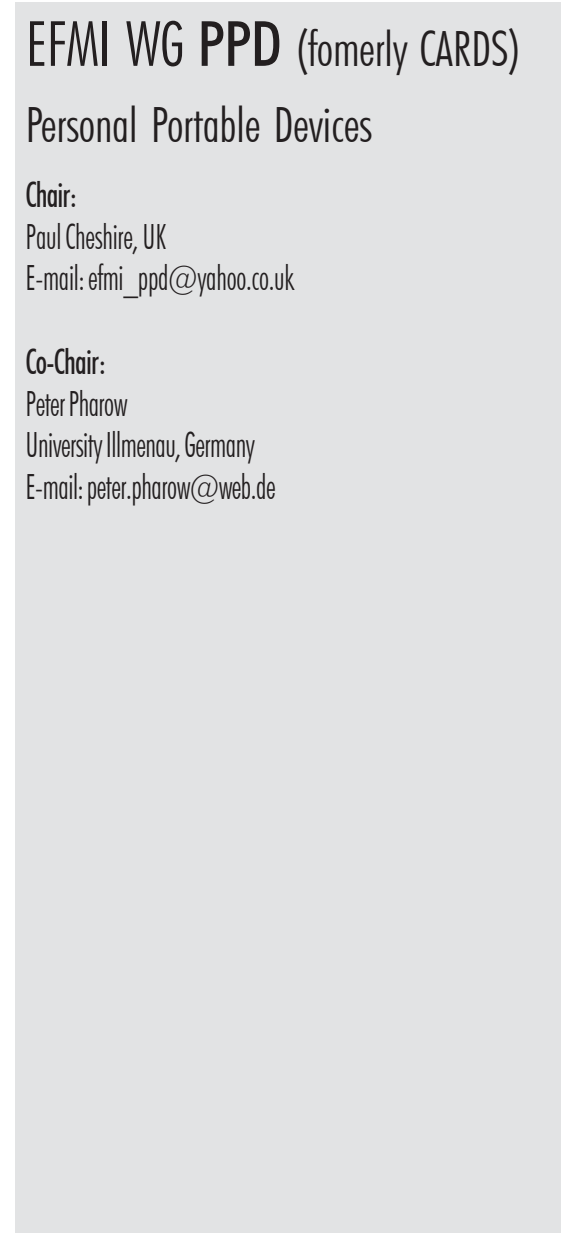

\section{EFMI WG SSE}

\section{Security, Safety and Ethics \\ Chair: \\ Bernd Blobel \\ eHealth Competence Center \\ University of Regensburg Medical Center \\ Regensburg, Germany \\ E-mail: bernd.blobel@klinik.uni-regensburg.de \\ hitp:///www.EFMl.org}

\section{Objectives:}

EFMI WG PPD (formerly WG CARDS) aims at being a European competence centre to monitor ongoing activities and to provide knowledge to policy makers and systems designers involved in projects related to personalised, portable devices (PPD) such as cards, tokens, sensors, actuators, and similar technologies in the domain of healthcare and welfare:

- Competence and know-how focused on health care identity management (ID), identification, and role management (entitlement) schemes

- Vision of personalised portable device technology applications

- Marketing, dissemination and deployment of WG ideas and results on national and European level including research projects and networks of excellence.

\section{Recent and Future Activities:}

- Seminar on PPD and sensor networks in the context of the pHealth 2009 workshop in Oslo, Norway, June 24 $4^{\text {th }}$ to $26^{\text {th }}, 2009$.

- Workshop on PPD, sensors, actuators, and related healthcare and welfare applications, MIE 2009, Sarajevo,

- Session on PPD and related technologies, EFMI STC 2009, Antalya, Turkey

- Workshops at pHealth 2010, Berlin, Germany, May 2010 and at eHealth 2010, Vienna, Austria, May) in cooperation with ETSI and IMIA WG AAL.

EFMI WG PPD co-operates with Standard Development Organisations (SDOs) (especially ISO TC 215, CEN TC 251, CEN TC 224, ISO/IEC JTC 1, and ETSI), EHTEL, World ID steering committee and other relevant organisations.

The activity plan is being resumed on a yearly basis. It includes several means of active participation in various scientific events (workshop, session, presentations, papers, etc.).

\section{Objectives:}

Speeding up the use of ICT for health care increases the challenge for trustworthiness, security and safety of solutions and infrastructure deployed. The WG aims to promote development, education and training on the field of security and privacy in health care. Close collaboration with other EFMI-WGs and beyond as well as with IMIA WG4 as for securing their ICT solutions for health care.

\section{Recent and Future Activities:}

- Tutorial „eHealth Platforms for Personal Health: Architecture, Policies, Models, Security and Privacy Requirements and Solutions“" at MIE 2009, Sarajevo

- Contribution to the PPD-Workshop „Portable Devices, Sensors and Networks: Wireless Personalized eHealth Services“" at MIE 2009, Sarajevo*

- Contribution to the Workshop „The Role of Ontologies in Interoperability“ at World Congress on Medical Physics and Biomedical Engineering, 2009, Munich, Germany, jointly organized with ICMCC*

- Contribution to the IMIA WG4 Working Conference „Trustworthiness of health information", 2009, Hiroshima, Japan

- Workshop at the EFMI STC 2010, Reykjavík, Iceland*

- Workshop at ICMCC 2010 in London, UK.*

Activities results are published.

* together with WG EHR 


\section{EFMI WG TRACE}

\section{Traceability of supply chains}

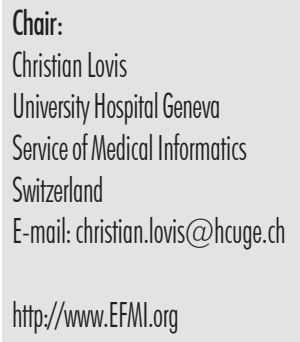

\section{Objectives:}

Traceability is an important aspect of health informatics and

- builds the net of information between supply chains, care processes, outcomes and financial flows.

- faces important challenges, such as entities identification and authentication and serialization

- implies to track and trace physical entities and linking these entities to virtualized

- information flows. The major benefits of traceability are

- improving efficiency and safety of care processes, including the supply chain of drugs, devices, etc.;

- improved secondary usage of data for outcome research;

- measures against counterfeited drugs and devices.

\section{Recent and Future Activities:}

The WG is growing. Several works have been undertaken in collaboration with GS1, such as

- mapping the GS1 system with the HL7-RIM model

- launching a working group for the global identification of actors

- organisation of a Survey on IT support to the decision \& supply chains

- co-organisation of the STC2010 conference with a focus traceability and a joint conference between HL-7 and GS1 